\title{
Delayed onset of a second paraneoplastic neurological syndrome in eight patients.
}

François Ducray ${ }^{1,5}$; Francesc Graus ${ }^{2}$, Maria Claudia Vigliani ${ }^{3}$, Jean-Christophe Antoine ${ }^{4,5}$, Veronique Rogemond ${ }^{1,5}$, Albert Saiz ${ }^{2}$, Jérôme Honnorat $\mathrm{PhD}^{1,5}$

1 - Hospices Civils de Lyon, Hôpital Neurologique, Centre de Référence Maladie Rare “Syndromes Neurologiques Paranéoplasiques”, Lyon, F-69003 France

2 - Department of Neurology, Hospital Clinic, Universitat de Barcelona and Institut d'Investigació Biomèdica August Pi i Sunyer (IDIBAPS), Barcelona, Spain

3 - Dipartimento di Neuroscienze, Università di Torino, Torino, Italy

4 - Hôpital Bellevue, Neurologie, Saint-Etienne, F-42100 France

5 - INSERM, U842, Lyon; Université Lyon1, UMR-S842, Lyon, F-69008 France

Disclosure: The authors have reported no conflicts of interest.

Correspondence to: Dr J. Honnorat, Neurologie B, Hôpital Neurologique de Lyon, 59 boulevard Pinel, 69677 Bron Cedex, France

Phone +(33) 4723578 08, Fax +(33) 4723573 29, e-mail jerome.honnorat@ chu-lyon.fr

The Corresponding Author has the right to grant on behalf of all authors and does grant on behalf of all authors, an exclusive licence (or non exclusive for government employees) on a worldwide basis to the BMJ Publishing Group Ltd to permit this article (if accepted) to be published in JNNP and any other BMJPGL products and sublicences such use and exploit all subsidiary rights, as set out in our licence. 


\section{Abstract}

Background: The occurrence of a second, delayed paraneoplastic neurological syndrome (PNS), different from the first, in the same patient is not well known. However, the recognition of this possibility is important in the management of the patients with PNS.

Objective: To describe eight patients who presented two different PNS with a time delay of months to years.

Design, setting and patients: Retrospective analysis of eight patients, included in the European PNS database, with two different PNS that occurred months to years apart. Results: The median delay between the two different PNS was 15 months. The antibody repertoire did not change between the two episodes. Anti-Hu was detected in five patients, anti-CV2 and anti-Ri in one each. One patient did not present onconeural antibodies. Lung cancer was diagnosed in six patients. In five patients, the second PNS revealed a cancer relapse $(n=4)$ or a second cancer $(n=1)$ and in three it occurred without evidence of tumor recurrence. In these three patients, all with anti-Hu antibodies, the second episode consisted of a lower motor neuron disease. Median survival was not reached after a median follow-up of five years.

Conclusions: A second PNS can reveal a cancer relapse but can also arise in its absence. The long survival of patients with a second PNS suggests that the immune response might be more effective in controlling the cancer. 


\section{Introduction}

Patients with paraneoplastic neurological syndrome (PNS) usually display a subacute, aggressive evolution and many patients die a few months after the diagnosis due to the combined effects of the neurological disability and cancer progression. In the most common PNS, paraneoplastic encephalomyelitis/sensory neuropathy associated with Hu antibodies, the median survival time is 11 months and the percentage of survivors beyond three years is less than 20\%. [1,2] The information on the clinical evolution of the PNS in those patients who survive more than three years is scarce. A recent study suggests that patients who are long term survivors of a PNS associated with anti-Hu antibodies slowly progress over the years despite the cancer is cured suggesting that the immune response may become independent of the original tumor trigger and keep active for many years. [3] In line with this observation, we found that anti-Hu antibody levels remain unchanged several years after remission of the tumor. In this study, two of the 35 patients included presented with a second, different PNS months or years after the diagnosis of the first PNS. [4] In the present study, we analyzed the clinical and immunological features of a series of eight patients who developed over the years two different types of PNS to ascertain their clinical profile and draw the attention to this possibility in patients followed with a PNS.

\section{Methods}

Data from the PNS (Paraneoplastic Neurological Syndrome) EURONETWORK Database (http://www.pnseuronet.org) collected between January 2000 and December 2008 (n=979) was retrospectively reviewed [5]. Patients with a second PNS different from the first one were identified in four centers (Barcelona $(n=3)$, Lyon $(n=2)$, Torino $(n=2)$, and Saint-Etienne $(\mathrm{n}=1))$. Patients' sera were tested for the presence of Hu-, Ri-, CV2/CRMP5-, Yo-, Ma2-, and 
amphiphysin-antibodies by immunohistochemistry and western blotting as previously described. [6]

\section{Results}

Patients' characteristics at the time of the first PNS are summarized in Table 1 (detailed case reports are provided as supplemental data). The median age was 54 years ( $42-71$ years). The first PNS episodes presented as a subacute sensory neuronopathy $(\mathrm{n}=2)$, a sensorimotor neuropathy $(\mathrm{n}=3)$, an opsoclonus-myoclonus $(\mathrm{n}=2)$, and a brainstem encephalitis $(\mathrm{n}=1)$. Serum screening for onconeural antibodies was positive in six patients: anti-Hu $(n=4)$, antiCV2/CRMP5 ( $\mathrm{n}=1)$, anti-Ri $(\mathrm{n}=1)$. This distribution was not different from the distribution in the 979 patients of the PNS EURONETWORK Database which contains $38.8 \%$ of anti-Hu $(n=380), 6 \%$ of anti-CV2/CRMP5 $(n=59), 5.1 \%$ of anti-Ri $(n=50)$ and $28.2 \%(n=276)$ without classical onconeural antibodies [5]. Associated cancers were SCLC $(n=4)$, carcinoid anaplastic lung tumor $(\mathrm{n}=1)$, prostatic adenocarcinoma $(\mathrm{n}=1)$, undifferentiated bronchial carcinoma $(n=1)$, and breast cancer $(n=1)$. After treatment of the underlying tumor in association with immunoactive drugs, the neurological condition improved in five patients and remained stable in three.

Patients' characteristics at the time of the second PNS are summarized in Table 2. In all patients, the second PNS was different from the first one and occurred without recurrence of the first one except in patient 6 in whom a mild worsening of the sensory neuronopathy was initially observed. Among the three patients in whom the first and second PNS consisted of a neuropathy (patients 2, 3 and 6), the second PNS (lower-motor neuron disease in patients 2 and 6, gastro-intestinal pseudo-obstruction in patient 3) could not just be considered as the worsening of the initial sensory neuropathy because none of these three patients had these symptoms at first PNS and the pathological substrate of the new symptoms represented the 
immune attack to another area of the nervous system (the spinal motorneurons or the myentheric plexuses). The median delay between the first and second PNS was 15 months (6-42). The diagnoses of the second PNS was encephalomyelitis $(n=1)$, chorea $(n=1)$, stiffperson syndrome $(n=1)$, dermatomyositis $(n=1)$, dysautonomia with gastro-intestinal pseudoobstruction $(n=1)$, and lower motor neuron disease $(n=3)$. In patients with CNS involvement MRI imaging and CSF studies ruled out metastatic disease. These second PNS episodes antedated a cancer relapse in four patients and a second cancer in one. In three patients, the second PNS occurred without evidence of cancer relapse despite repeated whole body PET scan imaging. Among the six patients who had an onconeural antibody, the same onconeural antibody was always found at the time of the second PNS. The titer of onconeural antibodies at both episodes was available in four patients: it remained stable $(n=2)$ or decreased, and eventually became undetectable, before increasing again $(n=2)$. In one patient, Hu antibodies were only detected at the time of the second PNS. Cancer was treated in all patients in whom the second PNS was associated with a cancer relapse or a second cancer. One patient (patient 6) was treated with chemotherapy even though no relapse of the SCLC was evident. Six patients received immunoactive treatments, which consisted of steroids $(n=4), \operatorname{IVIg}(n=4)$, cyclophosphamide $(n=1)$, and cyclosporine $(n=1)$. Three patients improved after treatment, two patients remained stable, and three patients experienced progression of the neurological deficit. After a median follow-up of 4.5 years after the first PNS, median survival has not been reached. Five patients are alive without relapse of the cancer, and four of these did not experience progression of the neurological symptoms. Three patients died, one from cancer relapse and two from evolution of the second PNS.

The second PNS consisted of a lower motor neuron disease in the three patients without evidence of cancer relapse. These patients had anti-Hu antibodies. In patient 6 , the lower motor neuron disease first involved the lower limbs before extending to the upper limbs, 
abdomen, and trunk. Anti-Hu antibodies became undetectable after the first PNS and reappeared at the onset of the lower motor neuron disease. CSF examination demonstrated only an elevated protein level $(0.75 \mathrm{~g} / \mathrm{L})$. Treatment included chemotherapy, despite no evidence of cancer relapse, followed by steroids, IVIg, and cyclosporine. However, the patient died of respiratory insufficiency after 5 years of evolution. No necropsy was performed. In patients 2 and 7, the lower motor neuron disease was localized. In patient 2, it was limited to the upper limbs, the trunk, and the abdomen. The CSF showed mild pleiocytosis (4 lymphocytes/mm3), elevated protein level $(0.6 \mathrm{~g} / \mathrm{L})$, and oligoclonal bands. After treatment with IVIg and cyclophosphamide, no progression of the lower motor neuron was observed. The patient is alive and stable 8 years after the onset of the lower motor neuron disease without evidence of cancer relapse. The lower motor neuron disease was limited to the legs in patient 7. CSF showed only an elevated protein concentration $(1.5 \mathrm{~g} / \mathrm{L})$. The patient was treated with steroids and he is alive and stable 4.5 years after the onset of the lower motor neuron disease without evidence of cancer relapse.

\section{Discussion}

The simultaneous involvement of different areas of the nervous system by the paraneoplastic process is not unusual and the term paraneoplastic encephalomyelitis (PEM) was introduced to define this syndrome that usually occurs in the setting of anti-Hu antibodies and lung cancer. [1] PEM is reported in 11\% of patients with PNS. [1] In contrast the simultaneous occurrence of two different, classical PNS, are less frequent. Well known examples are the coincidence of paraneoplastic cerebellar degeneration and Lambert-Eaton myasthenic syndrome associated with antibodies to calcium channels and lung cancer or the simultaneous development of sensory neuronopathy and gastrointestinal pseudoobstruction in patients with lung cancer and anti-Hu antibodies. [1, 7] The delayed onset of a second PNS seems to be 
much rarer since we identified only 8 cases with this condition $(0.8 \%)$ among the 979 patients of the PNS EURONETWORK database and found only one similar case in the literature. [8] Anti-Hu was the most commonly found onconeural antibody in patients with delayed onset of a second PNS. Although the second PNS was different from the first in all cases, the antibody repertoire did not change between the two episodes. In fact, in two patients (patients 1 and 3), the second PNS could be considered to be a different manifestation of the clinical syndrome usually associated with the underlying antibody. Indeed, polyneuropathy and chorea are two typical manifestations of the anti-CV2/CRMP5 syndrome, $[2,9,10]$ and sensory neuronopathy and gastro-intestinal pseudo-obstruction are two typical manifestations of the anti-Hu syndrome. [1] In 5 patients (62.5\%), the second PNS was clearly associated with relapse of the initial cancer or of a second cancer suggesting that cancer triggered the immune reaction responsible of the second PNS. However, in three cases, no cancer relapse was observed. Surprisingly, all this three patients had anti-Hu antibodies and similar lower motor neuron disease. About $15 \%$ to $20 \%$ of patients with anti-Hu syndrome show evidence of lower motor neuron involvement, but it is rarely the only manifestation. $[1,11,12]$ Because of the particular features of the lower motor neuron disease in these three patients, it is very unlikely that it corresponded to a degenerative motor neuron disease. [13] It rather suggests that the immune response had become independent of the cancer. Spontaneous complete remissions have been observed in patients with SCLC and anti-Hu antibodies; thus, an alternative hypothesis would be that a cancer relapse was not found because of effective anti-tumor immunity. [14] Whatever, this similar lower motor neuron syndrome in patients without tumor relapse suggests a common mechanism of immunization against motoneurons probably specific of $\mathrm{Hu}$ patients.

Finally, the last interesting characteristic of these patients was their prolonged survival. Median survival in the five patients with anti-Hu antibodies was not reached at five years. 
This result contrasts dramatically with the usual median survival reported in anti-Hu patients (11.8 to 18 months). [1,2] This suggests that in patients who develop a second PNS, the immune response is more aggressive but at the same time more effective in eradicating the cancer. 
Table 1: Patients' characteristics at the time of first PNS.

\begin{tabular}{|c|c|c|c|c|c|c|c|c|c|}
\hline & Age & Sex & First PNS & Rankin & Cancer & Antibodies & Cancer treatment & Immunotherapy & Evolution \\
\hline Patient 1 & 56 & M & $\begin{array}{l}\text { Subacute sensory motor axonal } \\
\text { polyneuropathy }\end{array}$ & 3 & SCLC & Anti-CV2 & $\begin{array}{l}\text { Chemotherapy and } \\
\text { radiotherapy }\end{array}$ & Steroids & $\begin{array}{l}\text { Improvement +++ } \\
\text { (Rankin 1) }\end{array}$ \\
\hline Patient 2 & 47 & M & Subacute sensory axonal polyneuropathy & 2 & $\begin{array}{l}\text { Undifferentiated bronchial } \\
\text { carcinoma }\end{array}$ & Anti-Hu & Surgery & None & $\begin{array}{l}\text { Improvement + } \\
\text { (Rankin 1) }\end{array}$ \\
\hline Patient 3 & 46 & M & Subacute sensory neuronopathy & 1 & SCLC & Anti-Hu & $\begin{array}{l}\text { Chemotherapy and } \\
\text { radiotherapy }\end{array}$ & Steroids & Stabilization \\
\hline Patient 4 & 54 & $\mathrm{~F}$ & Opsoclonus-myoclonus & 3 & Breast cancer metastasis & Anti-Ri & Surgery and hormonotherapy & IVIg and steroids & $\begin{array}{l}\text { Improvement }+++ \\
\text { (Rankin : 0) }\end{array}$ \\
\hline Patient 5 & 56 & $\mathrm{~F}$ & $\begin{array}{l}\text { Subacute sensory motor axonal } \\
\text { polyneuropathy }\end{array}$ & 3 & SCLC & None & Chemotherapy & None & $\begin{array}{l}\text { Improvement }+++ \\
\text { (Rankin 1) }\end{array}$ \\
\hline Patient 6 & 42 & $\mathrm{~F}$ & Subacute sensory neuronopathy & 3 & SCLC & Anti-Hu & $\begin{array}{l}\text { Chemotherapy and } \\
\text { radiotherapy }\end{array}$ & IVIg and steroids & Stabilization \\
\hline Patient 7 & 70 & $\mathrm{M}$ & Brain stem encephalitis & 4 & Prostatic adenocarcinoma & Anti-Hu & $\begin{array}{l}\text { Hormonotherapy and } \\
\text { radiotherapy }\end{array}$ & IVIg and steroids & Stabilization \\
\hline Patient 8 & 71 & M & Opsoclonus-myoclonus & 3 & Carcinoid bronchial tumor & None & Chemotherapy & IVIg and steroids & $\begin{array}{l}\text { Improvement +++ } \\
\text { (Rankin 0) }\end{array}$ \\
\hline
\end{tabular}

PNS: Pananeoplastic Neurological Syndrome; SCLC :Small cell lung cancer; IVIg= Intravenous immunoglobulins 
Table 2: Patients' characteristics at the time of second PNS

\begin{tabular}{|c|c|c|c|c|c|c|c|c|c|c|c|}
\hline & Second PNS & $\begin{array}{l}\text { Rankin } \\
\text { score }\end{array}$ & $\begin{array}{l}\text { Delay } \\
\text { (months) }\end{array}$ & $\begin{array}{l}\text { Tumor } \\
\text { recurrence }\end{array}$ & $\begin{array}{l}\text { Onconeural } \\
\text { antibodies }\end{array}$ & $\begin{array}{l}\text { Evolution of } \\
\text { onconeural } \\
\text { antibodies }\end{array}$ & $\begin{array}{l}\text { Treatment of } \\
\text { tumor } \\
\text { recurrence }\end{array}$ & Immunotherapy & Evolution & $\begin{array}{l}\text { Cause of } \\
\text { death }\end{array}$ & $\begin{array}{l}\text { Survival after first } \\
\text { PNS (years) }\end{array}$ \\
\hline Patient 1 & Chorea & 2 & 43 & Yes & Anti-CV2 & Unknown & Chemotherapy & $\begin{array}{l}\text { Steroids and } \\
\text { tiapride }\end{array}$ & Improvement & Alive & 9 \\
\hline Patient 2 & $\begin{array}{l}\text { Lower motor } \\
\text { neuron disease }\end{array}$ & 4 & 10 & No & Anti-Hu & Unknown & - & $\begin{array}{l}\text { IVIg and } \\
\text { cyclophos- } \\
\text { phamide }\end{array}$ & Stabilization & Alive & 9 \\
\hline Patient 3 & $\begin{array}{l}\text { Gastro-intestinal } \\
\text { pseudo- } \\
\text { obstruction }\end{array}$ & 4 & 23 & Yes & Anti-Hu & $\begin{array}{l}\text { Decrease and } \\
\text { relapse }\end{array}$ & Chemotherapy & None & Worsening & $\begin{array}{l}\text { Second PNS } \\
\text { evolution }\end{array}$ & 2.7 \\
\hline Patient 4 & $\begin{array}{l}\text { Stiff person } \\
\text { syndrome }\end{array}$ & 3 & 7 & $\begin{array}{l}\text { No, second } \\
\text { cancer: } \\
\text { hepato- } \\
\text { carcinoma }\end{array}$ & Anti-Ri & Stable & Surgery & IVIg & Improvement & Alive & 3 \\
\hline Patient 5 & Dermatomyositis & 1 & 10 & Yes: & none & Stable & - & IVIg and steroids & Improvement & $\begin{array}{l}\text { Brain } \\
\text { metastasis }\end{array}$ & 3 \\
\hline Patient 6 & $\begin{array}{l}\text { Lower motor } \\
\text { neuron disease }\end{array}$ & 4 & 82 & No & Anti-Hu & $\begin{array}{l}\text { Disappearance } \\
\text { followed by } \\
\text { relapse }\end{array}$ & $\begin{array}{l}\text { Chemotherapy } \\
\text { despite no } \\
\text { evidence of } \\
\text { recurrence }\end{array}$ & $\begin{array}{l}\text { IVIg, steroids and } \\
\text { cyclosporin }\end{array}$ & $\begin{array}{l}\text { Progressive } \\
\text { worsening }\end{array}$ & $\begin{array}{l}\text { Second PNS } \\
\text { evolution }\end{array}$ & 11 \\
\hline Patient 7 & $\begin{array}{l}\text { Lower motor } \\
\text { neuron disease }\end{array}$ & 4 & 6 & No & Anti-Hu & Stable & - & Steroids & Stabilization & Alive & 5 \\
\hline Patient 8 & Encephalomyelitis & 4 & 15 & Yes: & Anti-Hu & $\begin{array}{l}\text { Appearance of } \\
\text { anti-Hu }\end{array}$ & Chemotherapy & None & $\begin{array}{l}\text { Slow } \\
\text { worsening }\end{array}$ & Lost & 5 \\
\hline
\end{tabular}

PNS: Pananeoplastic Neurological Syndromes ; IVIg= Intravenous immunoglobulins 


\section{References}

1. Graus F, Keime-Guibert F, Rene R, et al. Anti-Hu-associated paraneoplastic encephalomyelitis: analysis of 200 patients. Brain 2001;124:1138-1148.

2. Honnorat J, Cartalat-Carel S, Ricard D, et al. Onco-neural antibodies and tumor type determine survival and neurological symptoms in paraneoplastic neurological syndromes with Hu or CV2/CRMP5 antibodies. J Neurol Neurosurg Psychiatry 2009; 80:412-416.

3. Poepel A, Jarius S, Heukamp LC, et al. Neurological course of long-term surviving patients with SCLC and anti-Hu syndrome. J Neurol Sci 2007;263:145-148.

4. Llado A, Mannucci P, Carpentier AF, et al. Value of Hu antibody determinations in the follow-up of paraneoplastic neurologic syndromes. Neurology 2004;63:1947-1949.

5. Giometto B, Grisold W, Vitaliani R, et al. Paraneoplastic neurological syndromes from the PNS-Euronetwork database. A European study from 20 centres. Arch Neurol, in press

6. Graus F, Delattre JY, Antoine JC, et al. Recommended diagnostic criteria for paraneoplastic neurological syndromes. J Neurol Neurosurg Psychiatry 2004;75:1135-1140.

7. Mason WP, Graus F, Lang B, et al. Small cell lung cancer, paraneoplastic cerebellar degeneration and the Lambert-Eaton myasthenic syndrome. Brain 1997;120:1279-1300.

8. Nagashima T, Mizutani Y, Kawahara H, et al. Anti-Hu paraneoplastic syndrome presenting with brainstem-cerebellar symptoms and Lambert-Eaton myasthenic syndrome.

Neuropathology 2003;23:230-238.

9. Vernino S, Tuite P, Adler CH, et al. Paraneoplastic chorea associated with CRMP-5 neuronal antibody and lung carcinoma. Ann Neurol 2002;51:625-630.

10. Yu Z, Kryzer TJ, Griesmann GE, et al. CRMP-5 neuronal autoantibody: marker of lung cancer and thymoma-related autoimmunity. Ann Neurol 2001;49:146-154. 
11. Forsyth PA, Dalmau J, Graus F, et al. Motor neuron syndromes in cancer patients. Ann Neurol 1997;41:722-730.

12. Verma A, Berger JR, Snodgrass S, et al. Motor neuron disease: a paraneoplastic process associated with anti-hu antibody and small-cell lung carcinoma. Ann Neurol 1996;40:112116.

13. Vigliani MC, Polo $\mathrm{P}$, Chio A, et al. Patients with amyotrophic lateral sclerosis and cancer do not differ clinically from patients with sporadic amyotrophic lateral sclerosis. J Neurol 2000;247:778-782.

14. Gill S, Murray N, Dalmau J, et al. Paraneoplastic sensory neuronopathy and spontaneous regression of small cell lung cancer. Can J Neurol Sci 2003;30:269-271. 